\title{
AS TIPOLOGIAS DE HABITATS DE INOVAÇÃO: UMA ANÁLISE DA LEGISLAÇÃO VIGENTE DO SUL DO BRASIL SOB LUZ DO NOVO MARCO LEGAL DE CIÊNCIA, TECNOLOGIA E INOVAÇÃO
}

\author{
Rossana Alves de Oliveira Simão Gomes ${ }^{1}$, Clarissa Stefani Teixeira ${ }^{2}$ \\ ${ }^{1}$ rossanaoliveira.alves@gmail.com \\ ²lastefani@gmail.com
}

\section{Resumo}

Este artigo apresenta um comparativo entre as Leis de Inovação dos Estados da Região Sul do Brasil (Santa Catarina, Rio Grande de Sul e Paraná) e a Lei de Inovação Federal no que diz respeito à previsão expressa das tipologias de habitats de inovação. $\mathrm{O}$ estudo revela que os estados apoiam principalmente a implantação de parques e incubadoras. Além disso, outras tipologias ainda não são estabelecidas o que reflete a realidade brasileira em termos de número de habitats de inovação disponíveis para o apoio do empreendedorismo e da inovação.

Palavras Chave: Inovação. Marco Legal de Inovação. Habitats de Inovação.

\section{THE TYPOLOGIES OF HABITATS OF INNOVATION: AN ANALYSIS OF THE LEGISLATION IN THE SOUTH OF BRAZIL UNDER THE NEW LEGAL FRAMEWORK OF SCIENCE, TECHNOLOGY AND INNOVATION.}

\begin{abstract}
This article presents a comparison between the Innovation Laws of the Southern States of Brazil (Santa Catarina, Rio Grande do Sul and Paraná) and the Federal Innovation Law in relation to the express prediction of the typologies of innovation habitats. The study reveals that states primarily support the implementation of parks and incubators. In addition, other typologies have not yet been established, reflecting the Brazilian reality in terms of the number of innovation habitats available to support entrepreneurship and innovation.
\end{abstract}

Keywords: Innovation. Legal Framework for Innovation. Innovation Habitats.

\section{Introdução}

A inovação tem sido considerada como uma espécie de catalisadora para o crescimento econômico da sociedade moderna. Dado ao avanço científico e tecnológico, novos padrões de desenvolvimento econômico estão surgindo. Nos últimos anos, o Brasil tem feito progresso na formulação de políticas públicas de apoio à inovação (PACHECO, 2007). O assunto inovação tem sido visto como prioridade na agenda de ciência e tecnologia nacional e, portanto, políticas e incentivos têm sido implementados pelo governo brasileiro (LUZ, et al, 2014).

Em nível nacional, a Lei n 10.973/2004, consagrada como Lei de Inovação, é um dos marcos regulatórios da política nacional de inovação e traça diretrizes gerais visando o fomento à inovação e à pesquisa científica e tecnológica no ambiente produtivo, para a capacitação e o alcance da autonomia tecnológica e o desenvolvimento industrial do país (Brasil, 2004). Em 2016, com a publicação da Lei 13.243/2016 (Brasil, 2016), denominada Marco Legal da Ciência, Tecnologia e Inovação (CT\&I), ao alterar a Lei de Inovação, o governo federal buscou desburocratizar as atividades de pesquisa e inovação no Brasil, incentivando ainda mais a R. Eletr. do Alto Vale do Itajaí - REAVI, v. 7, n. 11, p. 01-09, dez., 2018 ISSN: 2316-4190, DOI: $10.5965 / 2316419007112018010$ 
aproximação e interação entre as instituições científicas e tecnológicas (ICTs), as universidades, o setor produtivo e o estado. Em fevereiro de 2018, com o objetivo de regulamentar tanto a Lei de Inovação quanto o Marco Legal de CT\&I, foi promulgado o Decreto 9.283/2018 (BRASIL, 2018).

No âmbito estadual, analisando especificamente a região sul, o primeiro estado a ter lei de inovação foi Santa Catarina, em janeiro de 2008 com a promulgação da Lei 14.328/2008 (SANTA CATARINA, 2008). Em julho de 2009, Rio Grande do Sul também passou a ter sua lei local (13.196/2009) (RIO GRANDE DO SUL, 2009) e em setembro de 2012 o estado do Paraná, da mesma forma, codificou legislação específica para inovação com a publicação da Lei 17.314/2012 (PARANÁ, 2012).

Tanto na seara federal como estadual, dentre outros aspectos, as leis buscam fomentar a constituição de parcerias estratégicas entre os Institutos de Ciência e Tecnologia- ICTs, as universidades e as empresas, contribuindo, assim, para a criação de um cenário próprio ao desenvolvimento regional, ao empreendedorismo e à atração e fixação de investimentos de base tecnológica, favorecendo a prática da inovação (CAVALCANTE; FAGUNDES, 2007; MOREIRA ET AL, 2007). Para tanto, é necessário a criação de ambientes que de fato sejam propícios à conexão desses atores de inovação.

Nesse sentido, os habitats de inovação surgem como ambientes diferenciados que proporcionam interações entre os agentes de inovação (universidades, instituições de pesquisa, empresa e governo) visando o desenvolvimento do conhecimento, bem como alimentando os mecanismos de empreendedorismo e inovação da região, posto que une as habilidades, a tecnologia, os recursos e o conhecimento (LABIAK, 2012; LUZ ET AL., 2014; FERREIRA; TEIXEIRA, 2016). Estes ambientes são propícios à inovação por intermédio de compartilhamento de informações e conhecimentos favoráveis à inovação (LUZ, ET AL, 2014; TEIXEIRA ET AL, 2016).

Em que pese o esforço de criação de normas que fomentem o desenvolvimento desses ambientes, a falta de um conceito claro de habitat de inovação, bem como a previsão expressa das diversas tipologias de habitats existentes na bibliografia mundial, tem dificultado a conscientização dos governos regionais sobre a necessidade de criação desses ambientes considerados instrumentos de fortalecimento dos ecossistemas regionais de inovação.

Portanto, o objetivo deste trabalho é analisar as leis de inovação estaduais da região sul e a Lei de Inovação federal com objetivo de identificar o tratamento que tem sido dado aos habitats, bem como analisar os conceitos correlatos previstos no Decreto 9.283/2018 (BRASIL, 2018), demonstrando a necessidade de adequação dessa normativa, a fim de realizar um alinhamento conceitual que permita a formulação de políticas públicas que proporcionem o fomento desses ambientes propulsores de inovação, possibilitando, assim, a criação de um ecossistema vivo que promova desenvolvimento regional.

\section{Referencial Teórico}

No Brasil, as políticas de Ciência, Tecnologia e Inovação passaram a ter maior evidência a partir do início do século XXI. Segundo Pacheco (2007), as leis anteriores a 1999 (Lei de Biossegurança- n.8.974/95, Lei de Propriedade Industrial- n. 9279/96, Lei de Cultivares - n. 9456/97 e Lei do Software- n. 9609/98) em que pese consideradas importantes para regulamentação das atividades de $\mathrm{C} \& \mathrm{~T}$, quase não versaram sobre fomento, financiamento e incentivos à inovação.

A Lei de Inovação - Lei $n^{\circ}$ 10.973/2004 (BRASIL, 2004) é considerada um marco regulatório da política de inovação nacional e tem como objetivo o aumento da eficiência econômica e o desenvolvimento e difusão de tecnologias com maior potencial de indução do nível de atividade e de competição no comércio internacional.

R. Eletr. do Alto Vale do Itajaí - REAVI, v. 7, n. 11, p. 01-09, dez., 2018 ISSN: 2316-4190, DOI: $10.5965 / 2316419007112018010$ 
Em 2016, a Lei de Inovação foi alterada com a promulgação da Lei 13.243/2016 (Brasil, 2016), denominada como Marco Legal da Ciência, Tecnologia e Inovação, que veio com intenção de desburocratizar as atividades de pesquisa e inovação no Brasil. Em fevereiro de 2018, foi publicado o Decreto 9.283 (BRASIL, 2018), que veio para regulamentar, dentre outros dispositivos, as Leis n. 10.973/2004 - Inovação (BRASIL, 2004) e a n. 13.243/2016 - Marco da CT\&I (BRASIL, 2016), com objetivo de estabelecer medidas de incentivo à inovação e à pesquisa científica e tecnológica no ambiente produtivo, com vistas à capacitação tecnológica, ao alcance da autonomia tecnológica e ao desenvolvimento do sistema produtivo nacional e regional.

As leis estaduais de inovação tendem a seguir os dispositivos contidos na Lei Federal, adequando-se às especificidades estaduais, onde há previsão de medidas de incentivos a inovação - recursos de subvenção econômica e incentivos fiscais, no âmbito estadual (MENDES; OLIVEIRA; PINHEIRO, 2013). Assim, os estados, dentro de suas jurisdições, tem procurado replicar as proposições e instrumentos que são utilizados em âmbito nacional quando da formulação de políticas públicas de CT\&I. Em que pese existir uma repetição sistemática dos dispositivos contidos na lei federal, os estados possuem um repertório significantemente inferior de instrumentos de intervenção se comparados ao governo federal, como por exemplo o impedimento de legislar sobre matérias que versam sobre política cambial e monetária, posto que são de iniciativa exclusiva da união. Logo, em âmbito estadual, não é possível a imposição de barreira alfandegária com o objetivo de promover o desenvolvimento industrial e tecnológico regional (CAVALCANTE; FAGUNDES, 2007).

Entretanto, há instrumentos de inovação que tem características tipicamente regionais, como por exemplo, os habitats de inovação. Entretanto, dependendo da maturidade dos ecossistemas de inovação e empreendedorismo e da realidade já instalada nas regiões, se faz necessária a implantação de diferentes tipologias de habitats de inovação considerando o desenvolvimento regional.

Teixeira (2018) afirma que os habitats de inovação, na perspectiva dos órgãos governamentais, têm sido considerados instrumentos de políticas públicas. Neste sentido, os governos, em todos os níveis, ao formularem suas políticas públicas necessitam observar as necessidades de fomento à criação e desenvolvimento desses habitats, posto que são atores fundamentais para a consolidação de um ecossistema de inovação que possibilite o desenvolvimento regional.

Interessa destacar que o Estado brasileiro possui como fundamento da ordem econômica a livre iniciativa (art. 170, CF), devendo ser oferecidos meios de acesso à tecnologia, pesquisa e inovação por todos os entes políticos (BRASIL, 1988, art. 23, V). Nesta seara, portanto, há diversas formas de intervenção indireta do Estado na economia, a saber, por meio de indução (positivo ou negativo), fiscalização e planejamento (RIBEIRO, 2014, p. 16). No que importa ao presente trabalho, os instrumentos de indução positiva e planejamento são elementares para o desenvolvimento de habitats de inovação. Por indução positiva (fomento) pode-se entender o direcionamento dado pelo Poder Público aos agentes econômicos privados, operando-se pela construção de infraestrutura e financiamento de projetos por exemplo (PAULO, 2015). Já por meio do planejamento, "impede que o Estado atue de forma aleatória ou caprichosa" (PAULO; ALEXANDRINO, 2015, p.995), podendo identificar necessidades presentes e futuras dos diversos grupos sociais e orientar (por meio da indução positiva), a atuação dos agentes econômicos visando ao atendimento de fins determinados (PAULO; ALEXANDRINO, 2015).

\section{Procedimentos Metodológicos}

O presente estudo se classifica metodologicamente como exploratório (GIL, 2002). O estudo parte de uma análise documental da legislação vigente dos estados do Paraná, Santa Catarina e Rio Grande do Sul quanto à previsão de conceito de habitats de inovação, quanto às

R. Eletr. do Alto Vale do Itajaí - REAVI, v. 7, n. 11, p. 01-09, dez., 2018 ISSN: 2316-4190, DOI: $10.5965 / 2316419007112018010$ 
tipologias expressamente previstas e quanto os fomentos previstos para criação desses ambientes. Desta forma, as legislações analisadas foram:

- Paraná: Lei 17.314/2012

- Santa Catarina: Lei 14.328/2008

- Rio Grande do Sul: Lei 13.196/2009

Além disso, utilizou-se como análise comparativa a Lei n 10.973/2004 e o Decreto 9.283/2018. Da mesma forma, como maneira de discussão dos dados utilizou-se dados científicos, por meio de artigos e livros, identificados na literatura.

\section{Discussão e Resultado}

Embora o conceito de habitats de inovação venha sendo discutido por autores como Luz et al. (2014); Teixeira et al (2016); Teixeira, Almeida, Ferreira (2016); Teixeira et al. (2017), em nenhuma das Leis de Inovação estudadas há previsão de um conceito de habitats de inovação. A ausência desse conceito pode proporcionar relativa confusão quanto a caracterização de ambientes que de fato devem ser considerados como habitats de inovação, bem como, acaba por desestimular o investimento na criação desses ambientes.

Quanto às tipologias previstas nos textos legislativos, verifica-se que as quatro normas analisadas (Santa Catarina, Rio Grande do Sul, Paraná e Lei Federal de Inovação) trazem previsão expressa de apenas três tipos de habitats, quais sejam: Núcleos de inovação tecnológica (NIT), Parques Tecnológicos e incubadores. Cumpre salientar que, ao contrário do entendimento da bibliografia nacional especialista sobre o tema, as legislações analisadas não entendem os NITs como habitats/ ambientes de promotores de inovação, posto que se limitamse a conceitua-los e determinar suas competências. Estes dados refletem os achados quanto ao número de ambientes de inovação nos estados, onde prevalecem o número de incubadoras e parques.

Entretanto, o estudo de Teixeira (2018) indica que são consideradas diferentes tipologias de habitats de inovação como cidades, distritos, centros de inovação, parques, pré-incubadoras, incubadoras, aceleradoras, coworkings, núcleos de inovação tecnológica e ambientes makers. A Figura 1 ilustra as tipologias consideradas pelos autores. 


\section{$D$ Universidade do Estado de Santa Catarina Centro de Educação Superior do Alto Vale do Itajaí}

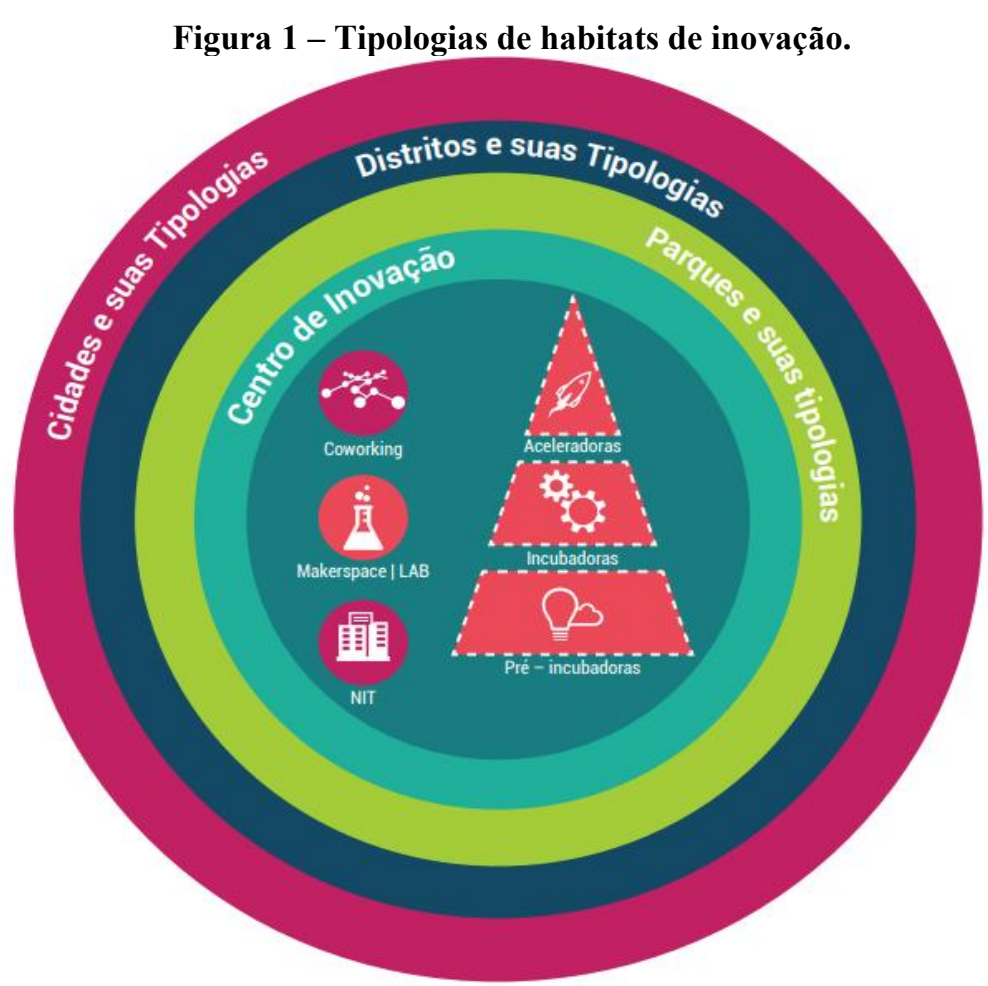

Fonte: Teixeira (2018).

Em que pese alguns pontos de convergência nos conceitos das tipologias existentes, é importante entender que cada um dos habitats citados tem sua especificidade e seu papel na interação e fortalecimento do ecossistema de inovação regional.

$\mathrm{Na}$ leitura detalhada das normas percebe-se que os habitats de inovação estariam, em tese, inseridos de forma genérica em seus textos, quando o legislador prevê fomento para criação de ambientes promotores de inovação. Ressalta-se que a Lei Federal, em seu Capítulo II, art. 3-B, incluído pelo Marco Legal de CTI (Lei 13.243/2016), prevê o apoio da União, dos Estados, do Distrito Federal, dos municípios, das respectivas agências de fomento e das ICTs para a criação, implantação e consolidação desses denominados ambientes promotores de inovação, incluindo os parques e polos tecnológicos e incubadores. Em momento algum conceitua o que de fato podem ser considerados ambientes promotores de inovação, porém, diante da leitura sistematizada do dispositivo, infere-se que parques tecnológicos e incubadoras são espécies de ambientes promotores de inovação.

Já a Lei de Inovação de Santa Catarina, em seu art. 25, prevê que a Secretaria de Estado do Desenvolvimento Econômico Sustentável proporá ao Conselho Estadual de Ciência, Tecnologia e Inovação (CONCITI) a política de parques tecnológicos, incubadoras de empresas e outros ambientes de inovação. Assim como a lei federal, não define o que são os ambientes de inovação, porém insere os parques tecnológicos e as incubadoras como espécies desses ambientes (SANTA CATARINA, 2008).

Ao contrário da lei federal e de Santa Catarina, a Lei de Inovação do Rio Grande do Sul, não trata de ambientes promotores de inovação, restringindo-se, apenas, em prever, em seu art. 25, o apoio a criação de parques científicos e tecnológicos e incubadoras de empresas de base tecnológica. Portanto, não há previsão expressa na lei estadual para criação de ambientes promotores de inovação (RIO GRANDE DO SUL, 2009).

No estado do Paraná, no art. 5 da Lei de Inovação, há previsão para formação de aliança estratégica entre o estado, seus municípios e as agências de fomento para a criação de ambientes de inovação, incluindo as incubadoras e os parques tecnológicos (PARANÁ, 2012).

R. Eletr. do Alto Vale do Itajaí - REAVI, v. 7, n. 11, p. 01-09, dez., 2018 ISSN: 2316-4190, DOI: 
Com intuito de preencher a lacuna quanto a conceituação de ambientes promotores de inovação, o Decreto 9283/2018, em seu art. 2, II, traz o seguinte o conceito:

II - ambientes promotores da inovação - espaços propícios à inovação e ao empreendedorismo, que constituem ambientes característicos da economia baseada no conhecimento, articulam as empresas, os diferentes níveis de governo, as Instituições Científicas, Tecnológicas e de Inovação, as agências de fomento ou organizações da sociedade civil, e envolvem duas dimensões:

a) ecossistemas de inovação - espaços que agregam infraestrutura e arranjos institucionais e culturais, que atraem empreendedores e recursos financeiros, constituem lugares que potencializam o desenvolvimento da sociedade do conhecimento e compreendem, entre outros, parques científicos e tecnológicos, cidades inteligentes, distritos de inovação e polos tecnológicos; e

b) mecanismos de geração de empreendimentos - mecanismos promotores de empreendimentos inovadores e de apoio ao desenvolvimento de empresas nascentes de base tecnológica, que envolvem negócios inovadores, baseados em diferenciais tecnológicos e buscam a solução de problemas ou desafios sociais e ambientais, oferecem suporte para transformar ideias em empreendimentos de sucesso, e compreendem, entre outros, incubadoras de empresas, aceleradoras de negócios, espaços abertos de trabalho cooperativo e laboratórios abertos de prototipagem de produtos e processos;

O conceito de ambientes promotores de inovação apresentado no inciso II, do art. 2 do Decreto (BRASIL, 2018), em primeira análise, aproxima-se do conceito de habitats de inovação apresentado na bibliografia e já amplamente tratado na fundamentação teórica apresentada, assim como indicam os autores Luz et al. (2014); Teixeira et al. (2016); Teixeira, Almeida, Ferreira (2016); Teixeira et al. (2017). Porém, o conceito de ecossistema de inovação previsto na alínea "a" do inciso II apresenta diferenciais em termos de alinhamento conceitual. Em primeiro, quanto ao próprio conceito apresentado e, em segundo, quando inserido como uma das dimensões dos ambientes promotores de inovação.

Teixeira, Trzeciak e Varvakis (2017) apresentam o histórico da concepção do termo, bem como uma vasta revisão bibliográfica sobre o conceito de Ecossistema de Inovação. Dentre os conceitos apresentados, pode-se destacar diversos autores, assim como ilustra o Quadro 1.

Quadro 1 - Conceitos sobre ecossistema de inovação.

\begin{tabular}{|l|l|}
\hline \multicolumn{1}{|c|}{ Conceito } & \multicolumn{1}{|c|}{ Autor } \\
\hline $\begin{array}{l}\text { Consideram o ecossistema de inovação como uma rede de relações } \\
\text { em que a informação e talento fluem, por meio de sistemas de co- } \\
\text { criação de valor sustentado. }\end{array}$ & $\begin{array}{l}\text { Etzkowitz; } \\
(2000)\end{array}$ \\
\hline $\begin{array}{l}\text { Ecossistema de inovação refere-se aos sistemas inter } \\
\text { organizacionais, políticos, econômicos, ambientais e tecnológicos da } \\
\text { inovação, em que ocorre a catalisação, sustentação e apoio ao } \\
\text { crescimento de negócios. }\end{array}$ & $\begin{array}{l}\text { Jishnu, Gilhotra; Mishra } \\
\text { (2011); Russell et al. (2011) }\end{array}$ \\
\hline $\begin{array}{l}\text { Uma estrutura de rede que contempla ligações entre todos os } \\
\text { partícipes, ou seja, consumidores, provedores de serviço, } \\
\text { fornecedores para as empresas, além do ambiente. Essas ligações, } \\
\text { como ressaltam os autores, são responsáveis por mostrar o fluxo de } \\
\text { valor no ecossistema de inovação. }\end{array}$ & \begin{tabular}{l} 
Sakaki- bara (2007) \\
\hline $\begin{array}{l}\text { Os ecossistemas de inovação se constituem num conjunto de } \\
\text { indivíduos, comunidades, organizações, recursos materiais, normas }\end{array}$
\end{tabular} \\
\hline
\end{tabular}

R. Eletr. do Alto Vale do Itajaí - REAVI, v. 7, n. 11, p. 01-09, dez., 2018 ISSN: 2316-4190, DOI: $10.5965 / 2316419007112018010$ 


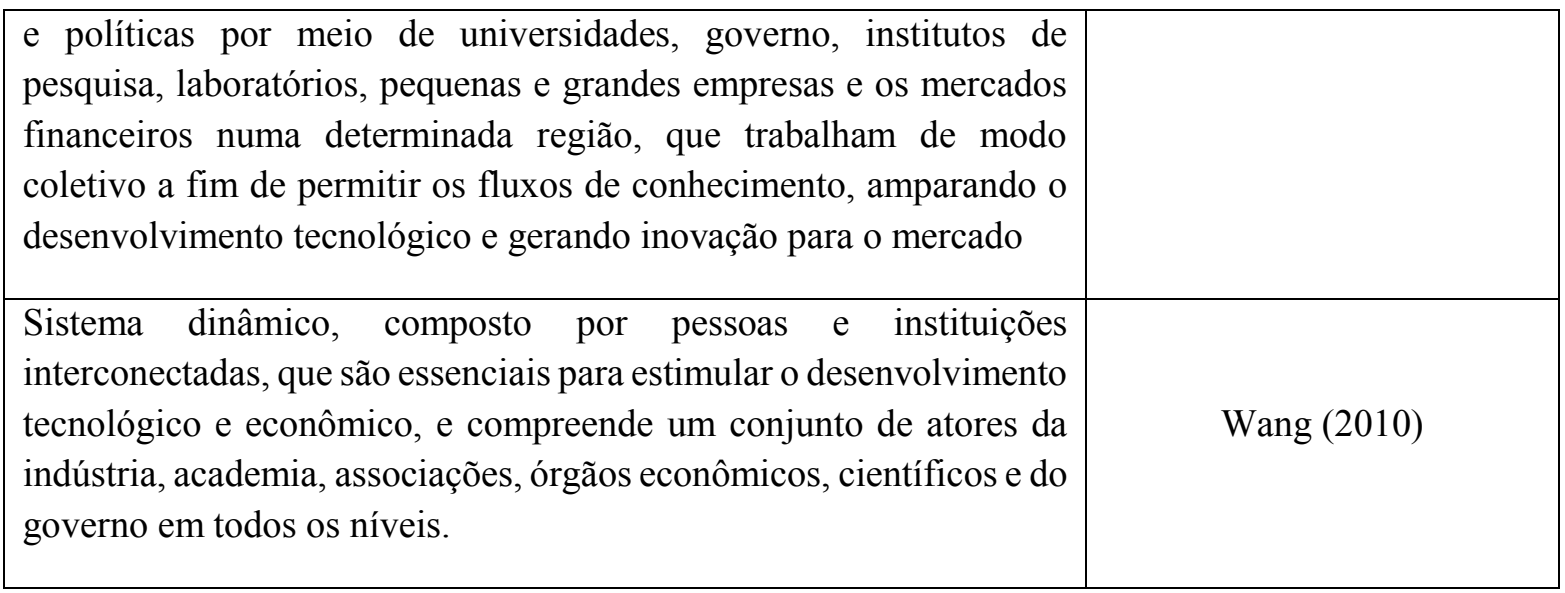

Fonte: Adaptado de Teixeira, Trzeciak e Varvakis, 2017.

Diante da revisão bibliográfica apresentada, verifica-se que ecossistema de inovação vai muito além de espaços físicos promotores de inovação, pois compreende-se na união imaterial dos mais diversos atores de inovação de determinada região, formando-se uma engrenagem invisível que propulsiona o desenvolvimento regional por intermédio da promoção do desenvolvimento tecnológico, da inovação e do empreendedorismo.

Se entendido ambientes promotores de inovação como sinônimo de habitats de inovação, percebe-se haver uma inversão de ordem dos conceitos, posto que os habitats de inovação ou ambientes promotores estão inseridos no ecossistema de inovação, fazendo, portanto, parte da engrenagem que fortalece o desenvolvimento regional e não ao contrário.

A alínea "a" do inciso II, art. 2 do Decreto traz, sob título de ecossistema de inovação, nada mais que os habitats de inovação sob a ótica das tipologias que dão suporte à interação entre universidades, ICTs, empresas e mercados e estimulam o fluxo de conhecimento e tecnologia entre esses agentes da inovação. Para tanto, a norma cita os parques científicos e tecnológicos, cidades inteligentes, distritos de inovação e polos tecnológicos (BRASIL, 2018).

Já na alínea "b" do mesmo inciso II, o Decreto conceitua mecanismos de geração de empreendimentos, porém percebe-se que o legislador novamente apresentou o conceito de habitats de inovação, só que dessa vez sobre a ótica das tipologias voltadas a dar suporte de infraestrutura física, qualificação e gestão aos empreendedores, afim de apoiar o desenvolvimento de empresas nascentes de base tecnológica. Para tanto cita as incubadoras de empresas, aceleradoras de negócios, espaços abertos de trabalho cooperativo (coworking) e laboratórios abertos de prototipagem de produtos e processos (fab labs e ambientes maker) (BRASIL, 2018).

Como se pode perceber é necessário que seja realizado um alinhamento conceitual de habitats de inovação/ambientes promotores de inovação nas legislações federais existentes, sob pena das leis estaduais e municipais que estão criadas ou reformuladas com base no novo marco legal de CT\&I e no Decreto regulamentador não estejam em alinhamento com as definições já tratadas pela literatura nacional e internacional o que, por consequência, dificultará a criação de políticas públicas para a criação desses ambientes tão fundamentais ao fortalecimento do ecossistema local.

\section{Conclusão}

Mesmo que as discussões em termos científicos venham ganhando um número maior de estudos nos últimos anos, ainda em termos estabelecidos na legislação vigente, pode-se dizer que não há incentivos de todas as tipologias de habitats de inovação, principalmente quando as legislações estaduais são analisadas.

R. Eletr. do Alto Vale do Itajaí - REAVI, v. 7, n. 11, p. 01-09, dez., 2018 ISSN: 2316-4190, DOI: $10.5965 / 2316419007112018010$ 
A ausência de previsão das demais tipologias pode implicar na falta de criação de políticas públicas que fomentem a criação desses ambientes e, por consequência, um enfraquecimento do ecossistema de inovação local que pode acarretar menor desenvolvimento regional. Ademais, há necessidade de especificar em termos legislativos, regulamentando estes ambientes, para que os governos possam de forma mais clara apoiar em políticas públicas.

Cabe destacar que as tipologias são diferentes em termos de objetivos e operações o que consequentemente necessita de diferentes apoios, esclarecimentos e fomentos em termos práticos. Logo, reafirma-se a necessidade dos habitats para fortalecimento do ecossistema de inovação local e desenvolvimento regional.

\section{Referências}

BRASIL. Constituição da República Federativa do Brasil. Promulgada em 05 de outubro de 1988. Disponível em: < http://www.planalto.gov.br/ccivil_03/constituicao/constituicao.htm > Acesso Agosto de 2018.

BRASIL (2004), Lei no 10.973, de 02 de dezembro de 2004. Dispõe sobre incentivos à inovação e à pesquisa científica e tecnológica no ambiente produtivo e dá outras providências. Disponível em: < http://www.planalto.gov.br/ccivil_03/_ato2004-2006/2004/lei/110.973.htm > Acesso em agosto de 2018.

BRASIL. Lei no 13.243, de 11 de janeiro de 2016. Dispõe sobre estímulos ao desenvolvimento científico, à pesquisa, à capacitação científica e tecnológica e à inovação e altera a Lei $\mathrm{n}^{\mathrm{o}}$ 10.973, de 2 de dezembro de 2004, a Lei $\mathrm{n}^{\mathrm{o}}$ 6.815, de 19 de agosto de 1980, a Lei $\mathrm{n}^{\mathrm{o}} 8.666$, de 21 de junho de 1993, a Lei $\mathrm{n}^{\mathrm{0}}$ 12.462, de 4 de agosto de 2011, a Lei $\mathrm{n}^{\mathrm{o}} 8.745$, de 9 de dezembro de 1993, a Lei no 8.958, de 20 de dezembro de 1994, a Lei no 8.010, de 29 de março de 1990, a Lei no 8.032, de 12 de abril de 1990, e a Lei no 12.772, de 28 de dezembro de 2012, nos termos da Emenda Constitucional no 85, de 26 de fevereiro de 2015. Disponível em: < http://www.planalto.gov.br/ccivil 03/_Ato2015-2018/2016/Lei/L13243.htm >Acesso agosto de 2018.

BRASIL. Decreto no 9.283, de 7 fevereiro de 2018. Regulamenta a Lei $\mathrm{n}^{\circ} 10.973$, de 2 de dezembro de 2004, a Lei $\mathrm{n}^{\circ} 13.243$, de 11 de janeiro de 2016, o art. 24 , $\S 3^{\circ}$, e o art. 32 , $\S 7^{\circ}$, da Lei ${ }^{\circ} 8.666$, de 21 de junho de 1993, o art. $1^{\circ}$ da Lei ${ }^{\circ} 8.010$, de 29 de março de 1990, e o art. $2^{\circ}$, caput, inciso I, alínea "g", da Lei $\mathrm{n}^{\circ} 8.032$, de 12 de abril de 1990, e altera o Decreto ${ }^{\circ}$ 6.759 , de 5 de fevereiro de 2009 , para estabelecer medidas de incentivo à inovação e à pesquisa científica e tecnológica no ambiente produtivo, com vistas à capacitação tecnológica, ao alcance da autonomia tecnológica e ao desenvolvimento do sistema produtivo nacional e regional. $<$ http://www.planalto.gov.br/ccivil 03/ ato2015-2018/2018/decreto/D9283.htm $>$ acesso em 15 de agosto de 2018.

CAVAlCANTE, L. R. M. T; Fagundes, M. E. M. Formulação de Políticas de Ciência, Tecnologia e Inovação em Nível Subnacional: Isomorfismo e Aderência às Realidades Regionais. Journal of Technology Management \& Innovation. v. 2, n. 2, p. 136-147, 2007. http://www.jotmi.org/index.php/GT/article/view/art51> acesso em Agosto de 2018.

FERREIRA, C. Z.; TEIXEIRA, C. S. Terminologia de habitats de inovação: Alinhamento conceitual (recurso eletrônico) - Florianópolis: Perse, 51p, 2016. : il. http://via.ufsc.br/wpcontent/uploads/2018/04/terminologia-de-habitats-de-inovacao.pdf $>$ acesso em Agosto de 2018.

R. Eletr. do Alto Vale do Itajaí - REAVI, v. 7, n. 11, p. 01-09, dez., 2018 ISSN: 2316-4190, DOI: $10.5965 / 2316419007112018010$ 
GIL, A. C. Como elaborar projetos de pesquisa. 4. ed. São Paulo: Atlas, 2002. $\square$

LABIAK JÚNIOR, SILVESTRE. Método de Análise dos Fluxos de Conhecimento em Sistemas Regionais de Inovação. 234 f. Tese (Doutorado em Engenharia e Gestão do Conhecimento) - Centro Tecnológico, Universidade Federal de Santa Catarina, Florianópolis. 2012. Disponível em: http://btd.egc.ufsc.br/wp-content/uploads/2012/06/Silvestre-LabiakJr.pdf Acesso em: 04 ago. 2018.

LUZ, A.A; KOVALESKI, J. L; ANDRADE, P.P; PENTEADO, R.F.S; ZAMAR, A. Habitats de inovação e a sinergia do potencial acadêmico, tecnológico e inventivo em Ponta Grossa, Paraná, Brasil. Revista Espacios, v. 35, n. 6. 2014. Disponível em: http://www.revistaespacios.com/a14v35n06/14350601.html> Acesso em agosto de 2018.

MENDES, D. R. F.; OLIVEIRA, M. A. C.; PINHEIRO, A. A. Política Nacional de Ciência, Tecnologia e Inovação: avaliação do marco regulatório e seus impactos nos indicadores de inovação. Revista de Empreendedorismo e Gestão de Pequenas Empresas, v. 2, n. 1, p. 2246, 2014. < file:///Users/rossanaoliveira/Downloads/49-240-1-PB.pdf

MOREIRA, N. V. A ; ALMEIDA, F.A.S; COTA,M.F.M; SBRAGIA,R. A Inovação Tecnológica No Brasil: Os Avanços No Marco Regulatório E A Gestão Dos Fundos Setoriais. Revista de Gestão USP, São Paulo, v. 14, n. especial, p. 31-44. 2007. Disponível em: < https://www.revistas.usp.br/rege/article/view/36580/39301> acesso em agosto de 2018.

PACHECO, C. A. As reformas da política nacional de ciência, tecnologia e inovação no Brasil (1999-2002). Manual de Políticas Públicas, Programa CEPALGTZ Modernización del Estado. Chile: CEPAL. 2007. https://www.cepal.org/iyd/noticias/paginas/5/31425/carlosamericop.pdf $>$ acesso em agosto de 2018.

PAULO, V; ALEXANDRINO, M (2015). Direito Constitucional Descomplicado. 14 Edição Rio de Janeiro: Forense; São Paulo: MÉTODO. 2015.

RIO GRANDE DO SUL, Lei estadual no 13.196, de 13 de julho de 2009. Estabelece medidas de incentivo à inovação e à pesquisa científica e tecnológica, define mecanismos de gestão aplicáveis às instituições científicas e tecnológicas do Estado do Rio Grande do Sul e dá outras providências. Disponível em: $<$ http://www.al.rs.gov.br/filerepository/repLegis/arquivos/13.196.pdf $>$. acesso em agosto de 2018.

RIBEIRO, A. W. A Efetividade Das Decisões Do Conselho Administrativo De Defesa Econômica (CADE). 131 f. Dissertação (Mestrado em Direito). Curso de Direito da Universidade de Marília, Marília. 2014. Disponível em: http://www.unimar.br/pos/trabalhos/arquivos/82276A89CA6D9FFB743804BFA1BFDE35.pd $\underline{\mathrm{f}}>$ acesso em Agosto de 2018 .

SANTA CATARINA, Lei estadual no 14.328, de 15 de janeiro de 2008. Dispõe sobre incentivos à pesquisa científica e tecnológica e à inovação no ambiente produtivo no Estado de Santa Catarina e adota outras providências. Disponível em: < https://www.legisweb.com.br/legislacao/?id=270420 $>$ acesso em agosto de 2018 .

R. Eletr. do Alto Vale do Itajaí - REAVI, v. 7, n. 11, p. 01-09, dez., 2018 ISSN: 2316-4190, DOI: $10.5965 / 2316419007112018010$ 
TEIXEIRA, C. S. Et al. Habitats de inovação: alinhamento conceitual. Florianópolis: Perse. 2016. Disponível em: <http://via.ufsc.br/download-habitats-deinovacao/>. Acesso em: Agosto de 2018.

TEIXEIRA, C. S. Apresentação. Habitats De Inovação e a Necessidade de Alinhamento Conceitual para Fortalecimento do Ecossistema. In. Habitats de inovação: conceito e prática / Ágatha Depiné; Clarissa Stefani Teixeira, organizadoras - São Paulo: Perse. 294p. v.1: il. 20181 e-book http://via.ufsc.br/wp-content/uploads/2018/05/HABITATS-DE-INOVACAOconceito-e-pratica.pdf $>$ acesso em agosto de 2018.

TEIXEIRA, C. S.; ALMEIDA, C. G.; FERREIRA, M. C. Z. Habitats de Inovação: alinhamento conceitual. 2017. Disponível em: $<$ http://via.ufsc.br/download-habitats-de-inovacao/ $>$ acesso em agosto de 2018 .

TEIXEIRA, C. S.; TRZECIAK, D. S.; VARVAKIS, G. Ecossistema de Inovação: alinhamento conceitual. Florianópolis: Perse, 2017. Disponível em: $<$ http://via.ufsc.br/download-ebookecossistemade-inovacao/>. Acesso em: agosto de 2018.

TEIXEIRA, M.M.C; EHLERS, A.C.S.T; REITZ, G; TEIXEIRA, C.S. Os habitats de inovação presentes nos parques científicos e tecnológicos de Santa Catarina. Revista Espacios, Vol. 39 (n. 06) pag. 22-29. $2017<$ http://www.revistaespacios.com/a18v39n06/a18v39n06p22.pdf $>$ Acesso em agosto de 2018. 